\title{
The Beneficial Use of Melanin in Inhibiting and Treating HCC Through Preventing CBC, Liver Enzymes, Oxidative Stress, and Lipid Peroxidation Alterations
}

Mohamed Anwar K Abdelhalim ( $\nabla$ abdelhalimmak@yahoo.com )

King Saud University https://orcid.org/0000-0002-3957-9078

Yanallah H Al-Mohy

King Saud University

Mohammed S Al-Ayed

King Saud University

Short Communication

Keywords: cancer, complete blood count, liver enzymes, oxidative stress, lipid peroxidation, melanin, rats

Posted Date: July 9th, 2020

DOI: https://doi.org/10.21203/rs.3.rs-40619/v1

License: (1) (i) This work is licensed under a Creative Commons Attribution 4.0 International License.

Read Full License 


\section{Abstract}

Hepatocellular carcinoma (HCC) accounts for more than $90 \%$ of primary liver cancers and is a major global health problem. The present application relates to normalizing abnormal levels of hematological blood parameters, oxidative stress indicators, and liver enzyme levels in the rats using melanin, and particularly, to treating their abnormal levels, in addition to evaluate the role of melanin during and after the progression of HCC, which will be supplemented histologically. Hematological blood parameters such as white blood cells (WBCs), red blood cells (RBCs), hemoglobin (HGB), hematocrit (HCT), and platelets (PLTs); liver enzymes such as alanine transaminase (ALT) and aspartate transaminase (AST); oxidative stress such as glutathione peroxidase (GSH-PX) and superoxide dismutase (SOD); LP malondialdehyde (MDA) were evaluated in all groups of rats. Injection of Diethylnitrosamine (DEN) and 2Acetyaminofluorine (2-AFF) induced HCC in the rats accompanied with a significant reduction in WBCs, RBCs, HGB, HCT, and PLTs, GSH-PX, and SOD; while a significant elevation was observed in ALT and AST, and MDA compared to the control. Melanin normalized all the above mentioned parameters during and after the progression of cancer towards their control values. These results demonstrate the beneficial use of melanin as a powerful antioxidant tool in inhibiting and treating HCC in the rats.

\section{Introduction}

HCC is the most common cancer-related death worldwide. Contemporary methods of cancer research have been influenced by data that reveal the importance of inflammatory components in the microbial environment. HCC is affected by factors such as DEN, 2-AAF, phenobarbital (PB), alcohol, and viruses (B and C) [1-2]. Clinical observations indicated a possible relationship between the bloodstream and malignancy in cancer. Therefore, clarifying tissue perfusion of organs or cancerous tissue is necessary to predict the growth of cancer and malignant tumor in tumor-carrying animals or in human cancer patients.

Unlike other tumors caused by the liver and digestive system, the cause of HCC is still sophisticated and mysterious, making the disease more complex and challenging. Cancer is a disease that affects the metabolism of the entire body rather than targeting the organs.

Animal models are critical tools for studying HCC. Due to the physiological and genetic similarities between rodents and humans, short age, reproductive ability and a variety of manipulation methods, animal models are often used for cancer research [3].

Several experimental animal models of HCC have been described over the past decades. Studies on the induction of liver cancer in rats use chemical agents such as DEN and 2-AAF [4]. 2-AAF shows its carcinogenic effect through the formation of DNA adducts, on the production of reactive oxygen species (ROS) and oxidized DNA damage [5]. DEN is a nitrosamine compound that stimulates the formation of liver cancer. DEN increased lipid peroxidation in studies conducted. This may increase the tumor [6-7]. The most acceptable suggested by Farber et al. [8], combines chemical induction by DEN with partial 
hepatic resection. Since then, DEN has been used to initiate liver cancer either alone or in conjunction with other cancer pathogens [9-11].

Advances in clinical and surgical treatments for cancer patients have increased overall survival rates. However, the growth of primary tumors and subsequent cancer tumors continue to cause deaths and prevent effective treatment $[12,13]$.

Clinical observations indicated a possible relationship between the bloodstream and malignancy in cancer $[14,15]$. Therefore, clarifying tissue perfusion of organs or cancerous tissue is necessary to predict the growth of cancer and malignant tumor in tumor-carrying animals or in human cancer patients.

Unlike other tumors caused by the liver and digestive system, the cause of HCC is still sophisticated and mysterious, making the disease more complex and challenging [16]. Cancer is a disease that affects the metabolism of the entire body rather than targeting the organs [17].

Liver function, which indicates the degree of liver damage, partially reflects the condition of the tumor biology. In clinical practice, patients with degraded liver function often had an unsatisfactory diagnosis compared to patients with acceptable criteria.

Few studies have associated the temporal development of oxidative stress (OS) with GSH-Px and SOD, and LP, such as MDA, and damage of cells involved in HCC formation. Understanding the changes that occur from pre-tumor lesions to cancer lesions in OS, LP, and liver inflammation and fibrosis can be important to improve knowledge about the transmission of chronic liver disease to HCC [9-11].

More recently, melanin has been extracted from various sources, and the immune role of melanin has been reported in plants and skin [18]. Many diseases are associated with an increase or decrease in melanin production. Melanin can be found in various organs, tissues and in the blood of living organisms. Melanin's ability to act as free-source feed has been demonstrated in vitro and in vivo [19].

The ability of melanin to act as an antioxidant has been proven to inhibit fat oxidation [20]. Melanin pigments are produced by melanocytes and are believed to act as antioxidants based on the belief that melanin can inhibit the electron-induced states and scavenge the free radicals $[19,20]$.

The present application relates to normalizing abnormal levels of hematological blood parameters, oxidative stress indicators, and liver enzyme levels in the patient using melanin, and particularly, to treating their abnormal levels caused by hepatocellular carcinoma.

It has become apparent that inflammation has a dual effect on the development of cancer. Thus, a method of normalizing hematological blood parameters and liver enzyme levels solving the aforementioned problems is desired. This study aims to generate HCC in rats, then to evaluate the total $\mathrm{CBC}$, liver enzymes, OS, and LP as well as to evaluate the role of melanin during and after the development of HCC which will be confirmed histologically. 


\section{Materials And Methods}

\section{Animals}

Forty Wistar-Kyoto male (120 $\pm 10 \mathrm{~g}, 4-6$ weeks) Obtained from the Central Animal House at the college of Pharmacy, King Saud University, Riyadh. They were housed in plastic (polypropylene) cages in groups of five rats per cage and kept in a room maintained at $25 \pm 2{ }^{\circ} \mathrm{C}$ with a 12-h light/dark cycle. By following the guiding standard for animal care and handling by KSU Local Animal Care and Use Committee Consideration. All experimental protocols were approved by KSU and/or licensing committee.

\section{Chemicals and reagents}

DEN and 2-AAF were purchased from Sigma Chemical Company, USA. All other chemicals and reagents were of the analytical grade were purchased from R\&D Systems Company, USA and Thermo Fisher Scientific Company, USA.

\section{Experimental protocols}

Rats were randomly divided into four groups of animals. The experimental design and treatment protocol were as follows: Group one $(\mathbf{G 1}, \mathbf{n = 1 0})$ normal control animals were orally administered saline. Group two $(\mathbf{G} 2, \mathbf{n}=\mathbf{2 0})$ injected i.p. with a single dose of $200 \mathrm{mg} / \mathrm{kg}$ body weight of diethylnitrosamine (DEN). After 1 week of recovery, the DEN-treated animals were dived into two groups. Group three $(\mathbf{G}, \mathbf{n}=10)$ were given repeated doses (150 mg/kg body weight) of 2-acetyaminofluorine (2-AAF) combined with $1 \%$ carboxymethyl cellulose as a promoting agent every three days for one month in combination with a melanin dose of $150 \mathrm{mg} / \mathrm{kg}$ body weight orally every two days for one month. Group four $(\mathbf{G} 4, \mathbf{n}=10)$ were only given repeated 2-AAF doses of $150 \mathrm{mg} / \mathrm{kg}$ body weight every three days for one month, After this period repeated melanin doses of $150 \mathrm{mg} / \mathrm{kg}$ body weight were given orally every two days for other one month.

\section{Preparation of tissues}

At the end of experimental periods, rats were anesthetized by inhalation of the ether, and blood was collected from the dorsal aorta. The serum was separated by centrifugation at $1200 \times \mathrm{g}$ for 10 minutes and stored at $-80^{\circ} \mathrm{C}$ prior to analysis. Their livers were immediately removed and divided into two parts, one in formalin $10 \%$ and the other under $-80^{\circ} \mathrm{C}$ for analysis.

\section{Complete blood count (CBC)}


Blood samples were collected in EDTA tubes, and hematological blood parameters such as white blood cells (WBCs), red blood cells (RBCs), hemoglobin (HGB), hematocrit (HCT), and platelets (PLTs) were evaluated using Full Blood Analysis CBC Genius KT-6400 Hematology Analyzer Device at King Khalid University Hospital, King Saud University, Riyadh.

\section{Biochemical estimation}

Examination of liver enzymes such as alanine transaminase (ALT) and aspartate transaminase (AST) were prepared using ELISA Gen 5 microplate reader. Examination of OS such as GSH-PX and SOD, and liver tissue LP (MDA) by liver tissue was prepared using ELISA Gen 5 microplate reader with GSH-PX Elisa kit, SOD Elisa and MDA in college of Pharmacy, King Saud University, Riyadh.

\section{Histological examinations}

For histological examination, hepatic sections of the liver were stained from different groups with hematoxylin and eosin ( $\mathrm{H} \& \mathrm{E})$. Briefly, at the end of the experiment, rats were anesthetized by the ether and transcardially perfused with saline. The liver was quickly removed and fixed in formalin buffered (10\%) for 24 hours. After fixation is complete, slices $(3-4 \mathrm{~mm})$ of these tissues were dehydrated and embedded in paraffin. At least four cross sections of each tissue were taken with a thickness of 5 microns and stained with $\mathrm{H} \& \mathrm{E}$. After two washing with xylene (2 min each), the tissue sections were fitted with a DPX mountant. The slides were observed for pathological changes. Microscopic images were taken using the Olympus BX50 microscope system (Olympus, Japan) at King Khalid University Hospital, King Saud University, Saudi Arabia.

\section{Results}

WBCs significantly ( ${ }^{*} \mathrm{p} \otimes 0.05$ ) reduced to $11.03 \pm 0.18\left(10^{3} \mathrm{cell} s / \mu \mathrm{L}\right.$ ) in $\mathrm{G} 2$ rats compared to $14.17 \pm 0.2$ $\left(10^{3} \mathrm{cells} / \mu \mathrm{L}\right)$ in control rats $(\mathbf{G 1})$. While WBCs in $\mathbf{G} 3$ and $\mathbf{G 4}$ rats significantly increased to $12.64 \pm 0.25$, $12.92 \pm 0.71\left(10^{3}\right.$ cells $\left./ \mu \mathrm{L}\right)$ respectively compared to $\mathbf{G} 2$ rats, but with no significant effect with $\mathbf{G} 1$ rats (Table 1).

RBCs significantly ( ${ }^{*} \mathrm{p} \otimes 0.05$ ) reduced to $7.12 \pm 0.17\left(10^{6} \mathrm{cells} / \mu \mathrm{L}\right)$ in $\mathrm{G} 2$ rats compared to $8.43 \pm 0.079$ $\left(10^{6} \mathrm{cells} / \mu \mathrm{L}\right)$ in control rats $\mathbf{G 1}$. While RBCs in $\mathbf{G} 3$ and $\mathrm{G} 4$ rats significantly increase to $8.17 \pm 0.12,7.99 \pm$ $0.1210^{6} \mathrm{cells} / \mu \mathrm{L}$ ) respectively compared with the $\mathbf{G} 2$ rats, but with no significant effect with $\mathbf{G} 1$ rats (Table 1).

Table. 1 represents $\mathrm{CBC}$ in four groups of the rats 


\begin{tabular}{|c|c|c|c|c|}
\hline Complete blood count (CBC) & Mean \pm SE $n=$ & & & \\
\hline $\begin{array}{l}\text { White Blood Cells (WBC) }\left(10^{3}\right. \\
\text { cells } / \mu \mathrm{L})\end{array}$ & $14.17 \pm 0.2$ & $\begin{array}{l}11.03 \pm \\
0.18^{*}\end{array}$ & $12.64 \pm 0.25^{\star a}$ & $12.92 \pm 0.71^{* a}$ \\
\hline $\begin{array}{l}\text { Red Blood Cells (RBC) }\left(10^{6} \text { cells/ }\right. \\
\mu \mathrm{L})\end{array}$ & $8.43 \pm 0.079$ & $\begin{array}{l}7.12 \pm \\
0.17 *\end{array}$ & $8.17 \pm 0.12^{\star a}$ & $7.99 \pm 0.12^{\star a}$ \\
\hline Hemoglobin (HGB) $(g / d L)$ & $154.2 \pm 1.5$ & $134 \pm 2.50 *$ & $\begin{array}{l}151.87 \pm \\
1.16^{* a}\end{array}$ & $\begin{array}{l}149.03 \pm \\
2.53^{\star a}\end{array}$ \\
\hline Hematocrit (HCT) (\%) & $46.44 \pm 1.14$ & $\begin{array}{l}41.46 \pm \\
0.65^{\star}\end{array}$ & $44 \pm 0.82^{\star a}$ & $45.69 \pm 1.52^{\star a}$ \\
\hline $\begin{array}{l}\text { Platelet count (PLTs) }\left(10^{3} \text { cells/ }\right. \\
\mu \mathrm{L})\end{array}$ & $\begin{array}{l}1127.33 \pm \\
20.5\end{array}$ & $\begin{array}{l}760 \pm \\
26.39 *\end{array}$ & $\begin{array}{l}1079.33 \pm \\
15.5^{\star a}\end{array}$ & $\begin{array}{l}994.67 \pm \\
20.34^{* a}\end{array}$ \\
\hline
\end{tabular}

HGB significantly ( ${ }^{*} \mathrm{p} \otimes 0.05$ ) reduced to $134 \pm 2.5(\mathrm{~g} / \mathrm{dL})$ in $\mathrm{G} 2$ rats compared to $154.2 \pm 1.5(\mathrm{~g} / \mathrm{dL}$ ) in control rats $\mathbf{G 1}$. While HGB in $\mathbf{G 3}$ and $\mathbf{G 4}$ rats significantly increase to $151.87 \pm 1,149.03 \pm 2.53(\mathrm{~g} / \mathrm{dL})$ respectively compared with the $\mathbf{G} 2$ rats, but with no significant effect with $\mathbf{G} 1$ rats (Table $\mathbf{1}$ ).

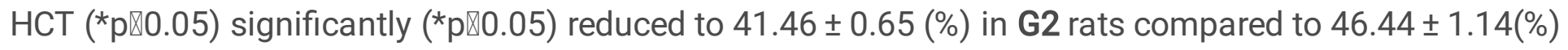
in control rats $\mathbf{G 1}$. While HCT in G3 and G4 rats significantly increase to $44 \pm 0.82,45.69 \pm 1.52(\%)$ respectively compared with the $\mathbf{G} 2$ rats, but with no significant effect with $\mathbf{G} 1$ rats (Table 1 ).

PLTs significantly ( ${ }^{*} \mathrm{p} \otimes 0.05$ ) reduced to $760 \pm 26.39\left(10^{3}\right.$ cells $/ \mu \mathrm{L}$ ) in $\mathrm{G} 2$ rats compared to $1127.33 \pm 20.5$ $\left(10^{3}\right.$ cells $\left./ \mu \mathrm{L}\right)$ in control rats $\mathbf{G 1}$. While PLTs in $\mathbf{G} 3$ and $\mathbf{G 4}$ rats significantly increase to $1079.33 \pm 15.5$, $994.67 \pm 20.34\left(10^{3}\right.$ cells $\left./ \mu \mathrm{L}\right)$ respectively compared with the $\mathbf{G} 2$ rats, but with no significant effect with G1 rats (Table 1$)$.

Fig.1 ALT significantly (*p囚0.05) increased to $56.31 \pm 3.2(\mathrm{U} / \mathrm{mg}$ ) protein in $\mathbf{G} 2$ rats compared to $25.23 \pm 1.8$ $(\mathrm{U} / \mathrm{mg})$ protein in control rats $\mathbf{G 1}$. While ALT in $\mathbf{G} 3$ and $\mathbf{G 4}$ rats significantly reduced to $43.81 \pm 3.1$, $50.02 \pm 3.05(\mathrm{U} / \mathrm{mg})$ protein respectively compared with the $\mathbf{G} 2$ rats, but with no significant (*apه0.05) effect with $\mathbf{G 1}$ rats.

Fig.2 AST significantly ( $\left.{ }^{*} \mathrm{p} \otimes 0.05\right)$ increased to $4.04 \pm 0.27(\mathrm{U} / \mathrm{mg})$ protein in $\mathbf{G} 2$ rats compared to rats $1.52 \pm 0.2(\mathrm{U} / \mathrm{mg})$ protein in control rats $\mathbf{G 1}$. While AST in $\mathbf{G} 3$ and $\mathbf{G} 4$ rats significantly reduced to $1.93 \pm 0.23,2.83 \pm 0.25(\mathrm{U} / \mathrm{mg})$ protein respectively compared with the $\mathbf{G} 2$ rats, but with no significant

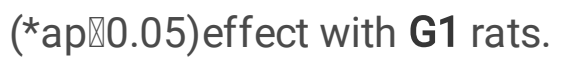

Fig.3 GSH-PX significantly (*p囚0.05) reduced to $5.2 \pm 0.55(\mathrm{U} / \mathrm{mg}$ ) protein in $\mathbf{G} 2$ rats compared to $8.54 \pm 0.49(\mathrm{U} / \mathrm{mg})$ protein in control rats $\mathbf{G 1}$. While GSH-PX in $\mathbf{G 3}$ and $\mathbf{G} 4$ rats significantly increase to $7.75 \pm 0.48,8.2 \pm 0.54(\mathrm{U} / \mathrm{mg})$ protein respectively compared with the $\mathbf{G} 2$ rats, but with no significant (*ap囚0.05) effect with $\mathbf{G 1}$ rats. 
Fig.4 SOD significantly ( $\left.{ }^{*} \mathrm{p} \otimes 0.05\right)$ reduced to $2.63 \pm 0.082(\mathrm{U} / \mathrm{mg})$ protein in $\mathbf{G} 2$ rats compared to $3.49 \pm 0.054(\mathrm{U} / \mathrm{mg}$ protein) in control rats $\mathbf{G 1}$. While SOD in G3 and $\mathbf{G 4}$ rats significantly increase to $3.32 \pm 0.105,3.23 \pm 0.075(\mathrm{U} / \mathrm{mg})$ protein respectively compared with the $\mathbf{G} 2$ rats, but with no significant (*ap囚0.05) effect with $\mathbf{G 1}$ rats.

Fig.5 MDA significantly ( $\left.{ }^{*} \mathrm{p} \otimes 0.05\right)$ increased to $0.639 \pm 0.021(\mathrm{U} / \mathrm{mg})$ protein in $\mathbf{G} 2$ rats compared to $0.19 \pm 0.015(\mathrm{U} / \mathrm{mg})$ protein) in control rats $\mathbf{G 1}$. While MDA in $\mathbf{G} 3$ and $\mathbf{G} 4$ rats significantly reduced to $0.543 \pm 0.032,0.442 \pm 0.041(\mathrm{U} / \mathrm{mg})$ protein respectively compared with the $\mathbf{G} 2$ rats, but with no significant (*ap囚0.05) effect with $\mathbf{G 1}$ rats.

Fig. 6 shows the change in the liver sections stained by H\&E. (A) section of the liver obtained from the control group. Central vein with surrounding normal hepatocytes was observed (H/E stain X 400). (B) Section of liver obtained from group 2. Note the emergence of a new population of atypical hepatocytes showing large nuclei (arrowhead) and coarse chromatin: H/E stain 600. (C)Section of liver obtained from group 3. Note the presence of some residual atypical hepatocytes indicative of partial improvement. Arrowhead is pointing towards a residual enlarged hepatocyte with abnormal nucleus (H/E stain X 600 ). (D) Section of liver obtained from G4. High power microscopic view showing many normal hepatocytes showing post mortem changes with one residual atypical hepatocytes showing a mitotic figure indicative of regeneration (arrowhead). The features are consistent with partial improvement with some compensatory regeneration (H/E stain X 600).

\section{Discussions}

In this study, injection of DEN and 2-AFF induced HCC in the rats. In these treated DEN + 2-AFF rats, a significant reduction in hematological parameters such as WBCs, RBCs, HGB, HCT, and PLTs was observed.

The number of WBCs has been reported to be more frequent in cancer patients with malignant tumors [21]. WBCs are produced by bone marrow and high WBCs indicate trauma, allergies, and leukemia or inflammation [22]. Other blood factors such as RBCs, HGB, HCT need further tests and studies to learn more about their relationship to cancer in general and liver cancer specifically.

PLTs are the primary mediators of pathological thrombosis [23]. Previous empirical evidence has shown that PLTs support tumor malignancy [24]. Platelet activation and thrombocytopenia have been shown to play a crucial role in the development of cancer. PLTs contribute to the survival of malignant tumor cells, suggesting that it may provide a new therapeutic way to treat metastatic cancer [25].

To evaluate importance of liver enzymes on the progression of cancer, we measured ALT and AST. Our study indicated significant elevation in ALT and AST compared to the control. Studies have shown that expressions of abnormal liver enzymes often lead to a bad diagnosis in many cancers. ALT and AST have been reported to influence the diagnosis in some cancers [26, 27]. 
There has been a significant increase in liver enzyme activity in the blood, especially when liver cell damage leads to liver function abnormalities. These enzymes (AST, ALT, and ALP) have been shown to exhibit higher activity in the abnormally functioning liver, demonstrating their presence as an indicator of liver function recovery in patients with liver transplantation [28]. A significant increase in AST, ALT and ALP serum levels was also reported after liver tumors were induced by $\mathrm{CCl} 4$ in mice [29]. While DEN has cancer, it is also a potent analgesic and shows toxicity.

Oxidative stress is a major factor during carcinogenesis [30]. Fat peroxide is one of the freest biologically studied free radicals series. It attacks the radical fatty acids or asyl fatty side chain of any chemical type which has sufficient interactivity to extract hydrogen atom from methylene carbon side chain. It may lead produce many toxic products such as MDA and 4-hydroxynonenal, which can attack DNA, stimulating cancer-causing mutations [30].

In our study, the hepatic GSH-PX and SOD levels were significantly reduced indicating an elevation in OS, while the MDA levels were significantly increased. Our data were in consistent with those reported [31]. Glutathione effectively wipe up all kinds of poisons and free radicals. Earlier results have elucidated the regulatory influence in GSH level in animals injected with natural antioxidants post ZnO-NPs administration. MDA is the main produce of fatty acid peroxidation, it has been confirmed to function as carcinogen, and it causes DNA damage by producing alterations in neoxyguanosine, deoxyadenosine and deoxycytidine, and leading to apoptosis [32].

The used melanin plays an effective hepatoprotective role against CBC count, AST, ALT, GSH-PX, SOD, and MDA alterations caused by DEN and 2-AAF toxicity. Co-administration of melanin to treated DEN and 2-AAF rats successfully and significantly returned the above mentioned to near their control values.

Our results were in consistent with those reported previously, in which melanin has many attractive properties, such as being an oxidizing agent in addition to its activities in removing free radicals $[18,33]$. Previous studies of melanin have revealed that melanin combines with oxygen-containing substances such as oxygen [34], radical hydroxyl, and negatively charged superoxide ion [33]. Melanin pigments can scavenge the free radicals $[19,20]$.

To completely confirm and insure the HCC, additional experiments related to DNA damage and ROS might be performed.

\section{Conclusions}

To generate cancer in the rats, the rats were injected with a single dose of DEN followed by repeated doses of 2-AAF for one month. According to an embodiment, melanin can be administered to a patient to normalize abnormal levels of hematological blood parameters, oxidative stress indicators, and liver enzyme levels in the patient. In an embodiment, the patient can be suffering from hepatocellular carcinoma (HCC). Hematological blood parameters can include white blood cells (WBCs), red blood cells (RBCs), hemoglobin (HGB), hematocrit (HCT), and platelets (PLTs). Liver enzymes can include alanine 
transaminase (ALT), aspartate transaminase (AST), liver glutathione peroxidase (GSH-PX), and liver superoxide dismutase (SOD). Oxidative stress parameters can include reactive oxygen species (ROS), and LP malondialdehyde (MDA). As described herein, HCC can cause a significant reduction in WBCs, RBCs, HGB, HCT, and PLTs, GSH-PX and SOD, while a significant elevation in ALT, AST, and MDA levels. The administration of melanin during and after the progression of HCC can return all of these parameters towards their normal control values.

\section{Declarations}

\section{Ethical Approval and Consent to participate}

All procedures concerning animal care as required for animal research of KSU were strictly followed.

\section{Availability of supporting data}

Not Applicable

\section{Competing interests}

The authors assert that they have no known conflict of interests.

\section{Patent Number}

Docket No. 33032.24

Re: Office Action in Patent Application for METHOD OF NORMALIZING BLOOD PARAMETERS, OXIDATIVE STRESS INDICATORS, AND LIVER ENZYME LEVELS USING MELANIN Serial No. 16/734,100

\section{Authors' contributions}

MAKA has participated in designing the study. MAKA and YHA carried out the practical work. MAKA and YHA have analyzed the data. MAKA, YHA, and MSA have prepared the manuscript draft. Final draft of manuscript has been modified and revised by MAKA. The final draft of the manuscript has been approved by all the authors.

\section{Acknowledgements}

\section{Funding:}

The authors would like to extend their sincere appreciation to the Deanship of Scientific Research at King Saud University for its funding of this research through the research Group Project No. RGP-285

\section{Conflict of Interest:}


The authors of this manuscript declare that they have no conflict of interest.

\section{Statement of Significance:}

These results demonstrate the beneficial use of melanin as a powerful tool in inhibiting and treating the HCC through preventing CBC, liver enzymes, oxidative stress, and lipid peroxidation alterations.

\section{References}

1. Kuroda HI, Ohtsuru AK, Futakuchi MI, Kawashita YU, Nagayama YU, Fukuda El, Namba HI, Shirai TO, Kanematsu TA, Yamashita SH. Distinctive gene expression of receptor-type tyrosine kinase families during rat hepatocarcinogenesis. International journal of molecular medicine.2002; 9(5):473-80.

2. Wood GA, Sarma DS, Archer MC. Inheritance of resistance to the promotion of preneoplastic liver lesions in Copenhagen rats. Experimental Biology and Medicine. 2001; 226(9): 831-835.

3. He L, Tian DA, Li PY, He XX. Mouse models of liver cancer: Progress and recommendations. Oncotarget. 2015; 6(27): 23306.

4. Itze L, Vesselinovitch SD, Rao KV. Estimation of the rate of DNA synthesis in newborn, regenerating and intact mice livers. Physiologia Bohemoslovaca. 1972; 22(5): 457-460.

5. Hasan SK, Sultana S. Geraniol attenuates 2-acetylaminofluorene induced oxidative stress,inflammation and apoptosis in the liver of wistar rats. Toxicology Mechanisms and Methods. 2015; 25(7):559-573.

6. Magee PN, Barnes JM. (1956). The production of malignant primary hepatic tumours in the rat by feeding dimethylnitrosamine. British journal of cancer. 1956; 10(1):114.

7. Yamada KI, Yamamiya I, Utsumi H. In vivo detection of free radicals induced by diethylnitrosamine in rat liver tissue. Free Radical Biology and Medicine. 2006; 40(11):2040-204.

8. E. Farber, D Solt, R Cameron, B Laishes, K Ogawa, A MedlineNewer insights into the pathogenesis of liver cancerAm. J. Pathol., 89 (1977), 477-482.

9. S. Malik, S Bhatnagar, N Chaudhary, DP Katare, SK JainDEN+2-AAF-induced multistep hepatotumorigenesis in Wistar rats: supportive evidence and insights Protoplasma, 250 (2013,175183

10. T Nagahara, J Okano, Y Fujise, R Abe, Y MurawakiPreventive effect of JTE-522, a selective cyclooxygenase-2 inhibitor, on DEN-induced hepatocarcinogenesis in rats Biomed. Pharmacother., 64 (2010), 319-326

11. DH Park, JW Shin, SK Park, JN Seo, L Li, JJ Jang, MJ LeeDiethylnitrosamine (DEN) induces irreversible hepatocellular carcinogenesis through overexpression of G1/S-phase regulatory proteins in rat

12. Maruvka $\mathrm{YE}$, Tang $\mathrm{M}$, Michor $\mathrm{F}$ On the validity of using increases in 5-year survival rates to measure success in the fight against cancer. PLoS One. 2014;23:e83100. 
13. Herrick AL, Clark S. Quantifying digital vascular disease in patients with primary Raynaud's phenomenon and systemic sclerosis. Ann Rheum Dis. 1998;57:70-78.

14. van der Hulle T, den Exter PL, Kooiman J, van der Hoeven JJ, Huisman MV, Klok FA. Meta-analysis of the efficacy and safety of new oral anticoagulants in patients with cancer-associated acute venous thromboembolism. J Thromb Haemost. 2014; 12:1116-1120.

15. Kuderer NM, Ortel TL, Francis CW. Impact of venous thromboembolism and anticoagulation on cancer and cancer survival. J Clin Oncol. 2009;27:4902-4911.

16. Patel T. Increasing incidence and mortality of primary intrahepatic cholangiocarcinoma in the United States. Hepatology. 2001; 33(6):1353-1357.

17. Patel T. Cholangiocarcinoma. Nat Clin Pract Gastroenterol Hepatol. 2006; 3(1):33-42.

18. Haseeb $A$, Elhag $H$, inventor; Haseeb $A$, Elhag $H$, assignee. Process for producing melanin using cultures of the genus Nigella. WIPO patent WO 2012125091A1. 2012 Sept 20. Available from: www.google.com/ patents/WO2012125091A1. Accessed June 08, 2018.

19. Korytowski W, Kalyanaraman B, Menon IA, Sarna T, Sealy RC. Reac- tion of superoxide anions with melanins: electron spin resonance and spin trapping studies. Biochim Biophys Acta 1986; 882(2):145-153.

20. Bustamante J, Bredeston L, Malanga G, Mordoh J. Role of melanin as a scavenger of active oxygen species. Pigment Cell Res. 1993; 6(5): 348-353.

21. Kahramanca S, Kaya O, Ozgehan G, et al. Are neutrophil-lymphocyte ratio and platelet-lymphocyte ratio as effective as Fournier's gangrene severity index for predicting the number of debridements in Fourner's gangrene? Ulus Travma Acil Cerrahi Derg. 2014; 20:107-112.

22. Min B, Brown MA, Legros G. Understanding the roles of basophils: breaking dawn. Immunology. 2012; 135:192-197.

23. Vadasz B, Chen P, Yougbaré I, et al. Platelets and platelet alloantigens: Lessons from human patients and animal models of fetal and neonatal alloimmune thrombocytopenia. Genes \& Diseases. 2015

24. Erpenbeck L, Schon MP. Deadly allies: The fatal interplay between platelets and metastasizing cancer cells. Blood. 2010; 115:3427-3436.

25. Gay LJ, Felding-Habermann B. Contribution of platelets to tumour metastasis. Nat Rev Cancer. 2011; 11:123-134.

26. Kim WR, Flamm SL, Di Bisceglie AM, Bodenheimer HC, Public Polic Committee of the American Association for the Study of Liver Disease Serum activity of alanine aminotransferase (ALT) as an indicator of health and disease. Hepatology. 2008; 47(4):1363-1370.

27. Faloppi L, Bianconi M, Memeo R, et al. Lactate Dehydrogenase in Hepatocellular Carcinoma: Something Old, Something New. Biomed Res Int. 2016; 2016:7196280.

28. Simonsen R, Uirji MA (1984) Interpreting the profile of liver-function tests in pediatric liver transplants. Clin Chem 30:1607-1610 
29. Kim DJ, Lee KK, Han BS, Ahn B, Bae JH, Jang JJ (1994) Biphasic modifying effect of indole-3carbinol on diethylnitrosamineinduced preneoplastic glutathione-S-transferase placental formpositive liver cell foci in Sprague-Dawley rats. Jpn J Cancer Res 5:378-383.

30. Banaker MC, Paramacivan SK, Chattopadhyay MB, Datta S, Chakraborty P, Chatterjee M, Kannan K, Thygarajan E (2004) 1a, 25-dihydroxyvitamin D3 prevents DNA damage and restores antioxidant enzymes in rat hepatocarcinogenesis induced by diethylnitrosamine and promoted by phenobarbital. World J Gasteroenterol 10:1268-1275.

31. ElObeid, Adila Salih, Afaf Kamal-Eldin, Mohamed Anwar K. Abdelhalim, and Adil M. Haseeb. "Pharmacological properties of melanin and its function in health." Basic \& clinical pharmacology \& toxicology 120, no. 6 (2017): 515-522.

32. Niedernhofer LJ, Daniels JS, Rouzer CA, Greene RE, Marnett LJ. Malondialdehyde, a product of lipid peroxidation, is mutagenic in human cells, J. Biol. Chem., 2003, 278: 31426-31433.

33. Bridelli MG, Ciati A, Crippa PR. Binding of chemicals to melanins re-examined: adsorption of some drugs to the surface of melanin particles. Biophys Chem. 2006; 119(2):137-145.

34. Perna G, Frassanito MC, Palazzo G, et al. Fluorescence spectroscopy of synthetic melanin in solution. J Lumin. 2009; 129(1):44-49.

\section{Figures}

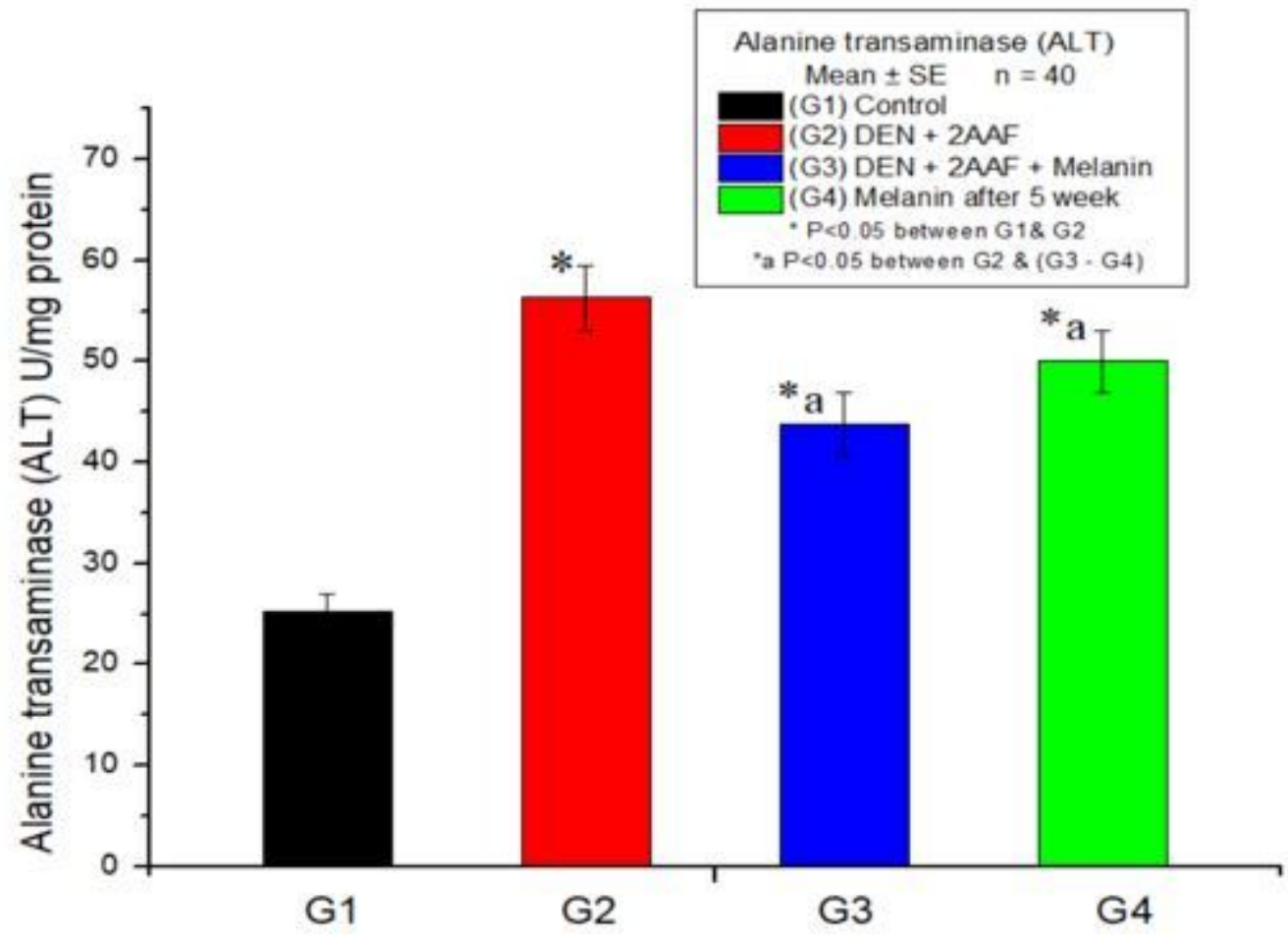

Figure 1

Change in Alanine transaminase (ALT) in four groups of the rats 


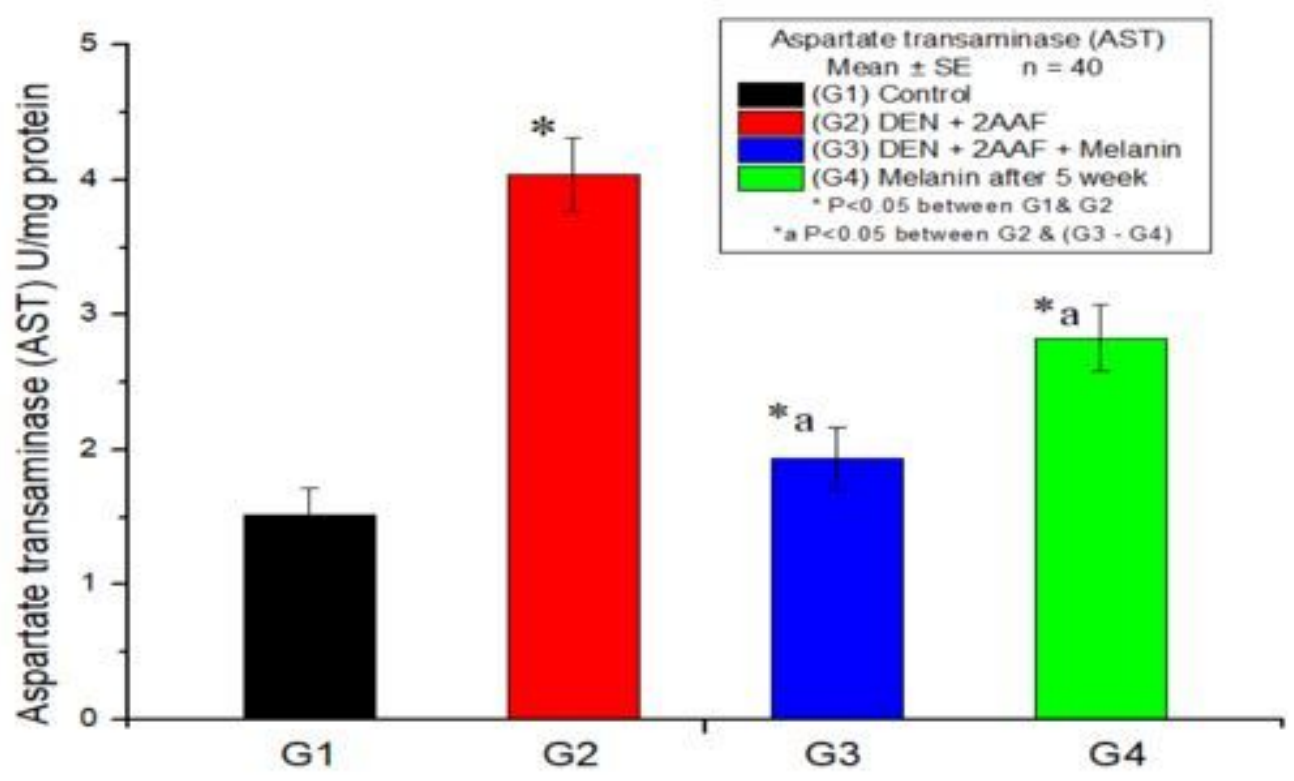

Figure 2

Change in Aspartate transaminase (AST) in four groups of the rats

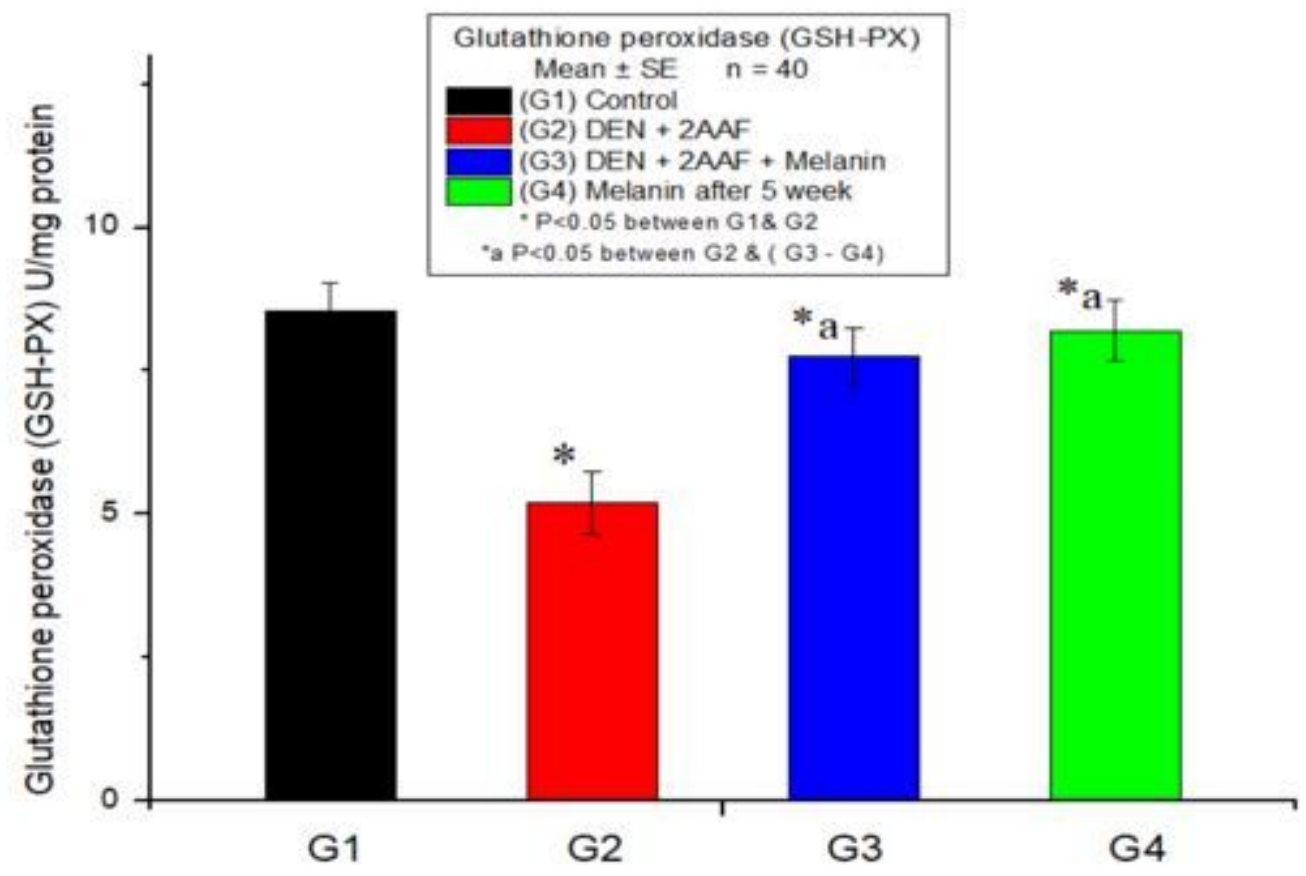

Figure 3

Change in glutathione peroxidase (GSH-PX) in four groups of the rats 


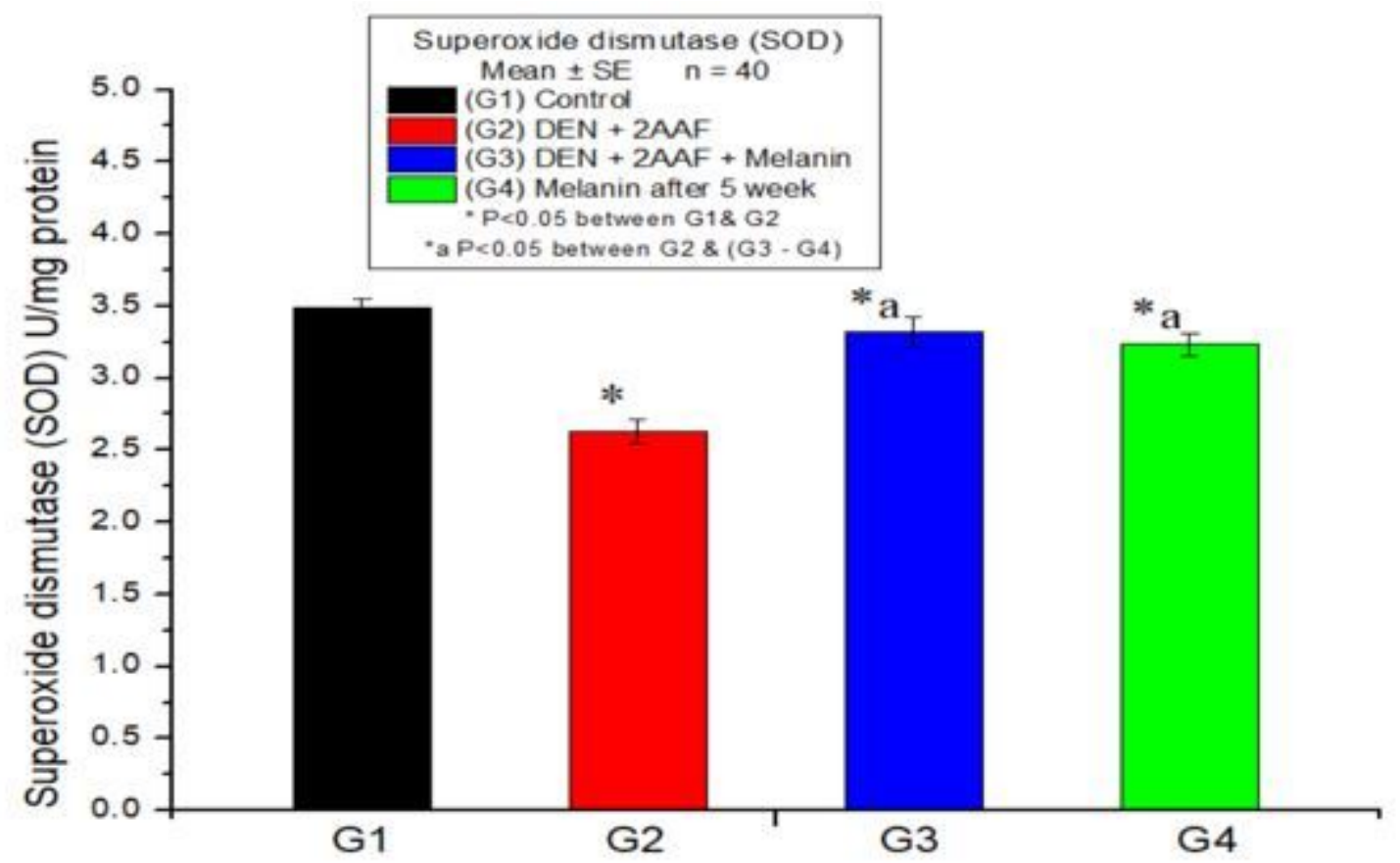

Figure 4

Change in Superoxide dismutase (SOD) in four groups of the rats

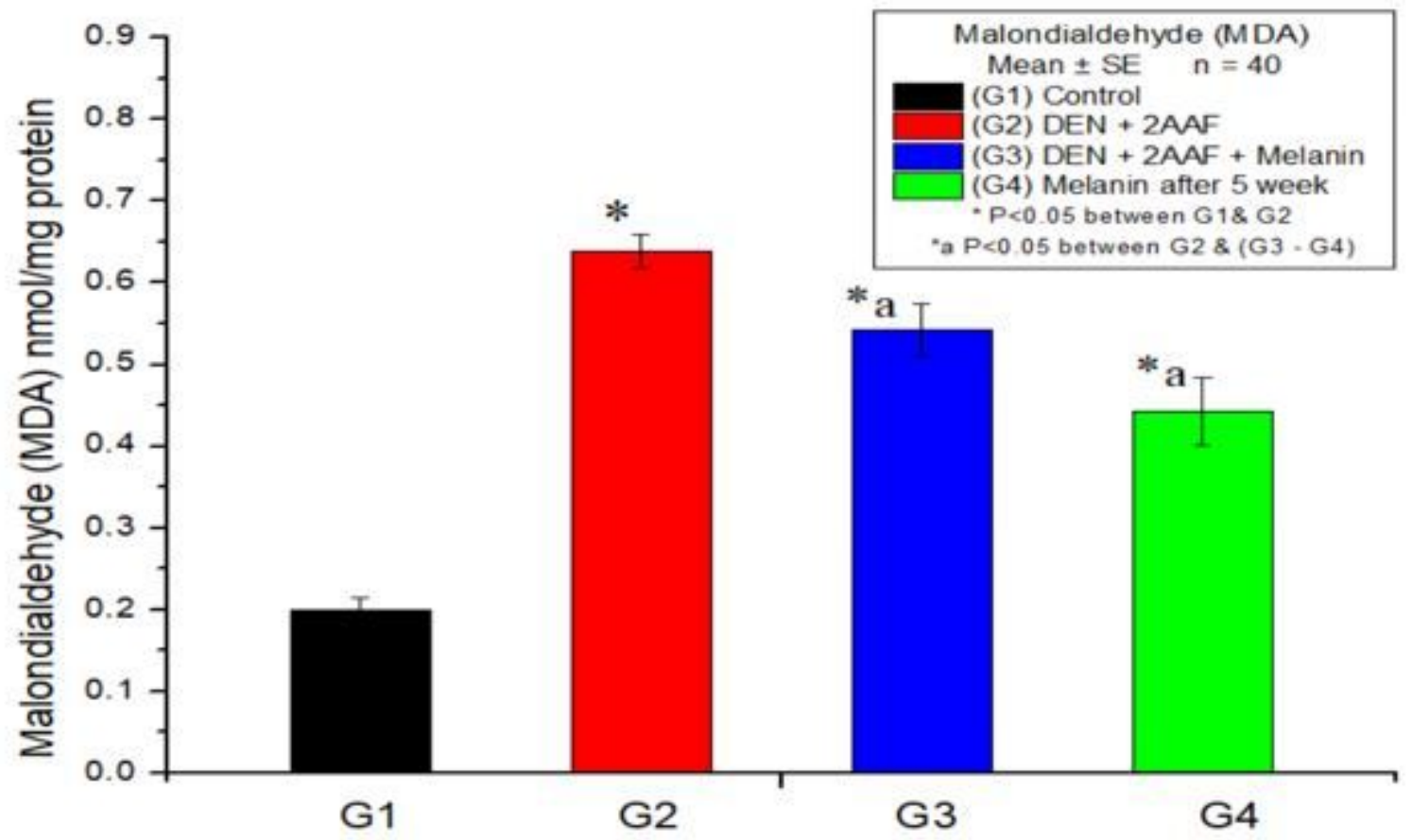

Figure 5

Change in malondialdehyde (MDA) in four groups of the rats 

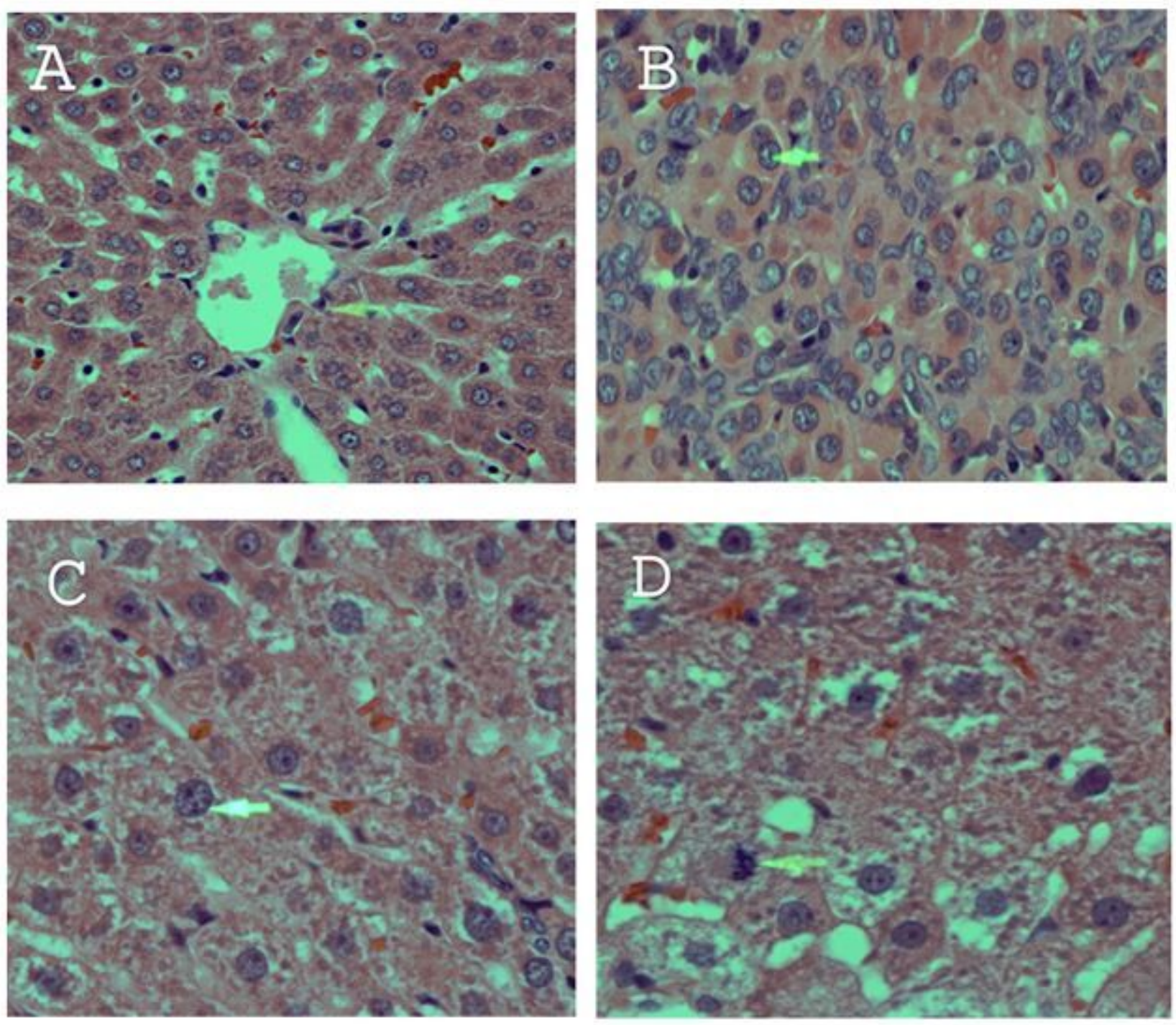

Figure 6

Photomicrographs of 400x. (A) G1: control rats. (B) G2: DEN+2AAF rats. (C) G3: DEN + 2AAF + Melanin rats. (D) G4: melanin after 5 weeks. 